\title{
DEGRADAÇÃO FOTOCATALÍTICA DE ATRAZINA NA PRESENÇA DE CATALISADORES NANOPARTICULADOS
}

\author{
Flávio Arantes Campos ${ }^{\mathrm{a}, *}$, Ana Carolina Ribeiro Aguiara, Victor Souza Medeiros ${ }^{\mathrm{a}}$, Adriene de Cássia Branquinho ${ }^{\mathrm{a}}$, Franco \\ Cesar Belchior da Silva ${ }^{a}$, Rômulo Davi Albuquerque Andrade ${ }^{b}$ e Andréa Rodrigues Chaves \\ anstituto Federal Goiano, Campus Rio Verde, 71901-971 Rio Verde - GO, Brasil \\ 'Instituto Federal de Goiás, Câmpus Luziânia, 72811580 Luziânia - GO, Brasil \\ 'Instituto de Química, Universidade Federal de Goiás, 74001-970 Goiânia - GO, Brasil
}

Recebido em 15/04/2016, aceito em 18/07/2016, publicado na web em 19/08/2016

\begin{abstract}
ATRAZINE PHOTOCATALYTIC DEGRADATION IN NANOPARTICLES CATALYSTS PRESENCE. Atrazine is a persistent herbicide and several studies have detected their presence in drinking water sources. In this work the atrazine photocatalytic degradation was investigated in aqueous solution using $\mathrm{TiO}_{2}, \mathrm{ZnO}$ and $\mathrm{TiO}_{2} / \mathrm{ZnO}$ catalysts. The catalysts were synthesized by Pechini's method and characterized by X-ray diffraction (XRD) and scanning electron microscopy (SEM). The process was monitored using absorption spectroscopy in ultraviolet and visible (UV-vis) region and high performance liquid chromatography (HPLC). The prepared catalysts were used in ultrafine powder form and its characterization showed nanometer order particle sizes. The atrazine absorbance decrease was observed after samples irradiation in catalysts presence and HPLC analysis showed a significant herbicide reduction and other compounds formation as degradation products. The $\mathrm{ZnO}$ catalyst use was more effective in atrazine molecule degradation compared to the other nanoparticles.
\end{abstract}

Keywords: atrazine; degradation; photocatalysis.

\section{INTRODUÇÃO}

Atualmente, se observa um aumento gradativo na utilização de pesticidas em diversos setores. O Brasil é o país que lidera o comércio mundial de agrotóxicos e, nos últimos dez anos, a demanda por estes produtos no mercado interno teve uma elevação de $190 \%$, enquanto que no mercado mundial o aumento foi de $90 \%$. Em 2012, as plantações brasileiras consumiram aproximadamente U\$ $\$ 7,3$ bilhões em agrotóxicos, o que equivale a $19 \%$ do mercado global. ${ }^{1}$

Esse aumento exacerbado no consumo de pesticidas, juntamente com o descuido nos processos de aplicação, oferece riscos ambientais que podem promover a contaminação de solos, de águas superficiais e subterrâneas e do ar. ${ }^{2}$

A presença de contaminantes na água pode causar graves problemas crônicos à saúde e dependendo da sua toxicidade e da ocorrência de exposição aguda, também podem se observar distúrbios em curto prazo como intoxicações e morte. Os efeitos crônicos podem ocorrer meses, anos ou até décadas após a exposição e se manifestam de várias formas como cânceres, malformações congênitas, distúrbios endócrinos e neurológicos, entre outros. ${ }^{3}$

Um herbicida que é muito utilizado nas culturas de milho, soja e cana-de-açúcar e vem sendo comumente detectado em águas superficiais, é a atrazina (2-cloro-4-etilamino-6-isopropilamino-1,3,5-triazina). Este herbicida apresenta solubilidade em solução aquosa de $33 \mathrm{mg} \mathrm{L}^{-1}$ à $27^{\circ} \mathrm{C}$ e possui tempo de meia-vida no solo que varia de 4 a 57 anos e em água superficiais de até 1 ano. Entretanto, um dos grandes problemas associados à atrazina é o fato de apresentar baixa adsorção e ser bastante estável, em baixas temperaturas, o que lhe fornece mobilidade e alta capacidade de lixiviação, podendo assim atingir diversas fontes de água. ${ }^{4}$

Os limites máximos estabelecidos para detecção de atrazina em águas de consumo são de $3,0 \mu \mathrm{L}^{-1}$ nos EUA, ${ }^{5} 0,1 \mu \mathrm{L}^{-1}$ na União

*e-mail: flavio.acampos@hotmail.com
Européia $^{6}$ e 2,0 $\mu . L^{-1}$ no Brasil. ${ }^{7}$ Na Europa, a detecção deste pesticida nas águas de consumo humano em níveis superiores ao limite máximo estabelecido fez com que sua utilização fosse proibida em alguns países e após uma reavaliação dos seus riscos ecotoxicológicos, a União Europeia revogou a autorização de formulações que contêm este composto como princípio ativo. ${ }^{8}$ Esta proibição ocorreu, principalmente, devido ao risco iminente de contaminação de águas com atrazina e seus subprodutos de degradação, em concentrações superiores à $0,1 \mu \mathrm{L}^{-1}$.

A constante presença de pesticidas nas águas de consumo, principalmente em regiões essencialmente agrícolas, se torna de extrema gravidade devido aos processos utilizados nas estações de tratamento de água serem ineficientes na remoção desses micropoluentes. ${ }^{9}$

Tendo em conta essa limitação, novos métodos de tratamento vêm sendo investigados e os processos oxidativos avançados (POAs) têm apresentado destaque alcançando resultados promissores na degradação de diversos micropoluentes, em especial, diferentes tipos de pesticidas. ${ }^{9,10}$

Os POAs são baseados na geração do radical hidroxila $(\mathrm{OH} \bullet)$ que tem alto poder oxidante e pode promover a degradação de vários compostos poluentes, em tempos relativamente pequenos. ${ }^{11}$

Dentre os POAs a fotocatálise heterogênea tem despertado especial atenção, principalmente, em função da utilização de catalisadores produzidos a partir de óxidos de metais semicondutores, que são irradiados promovendo a quebra de moléculas de poluentes orgânicos como, por exemplo, corantes de indústrias têxteis em água. O desenvolvimento dessa tecnologia se deu, especialmente, pelo uso de óxido de titânio anatase como catalisador. ${ }^{12}$

Diversos métodos de preparação de fotocatalisadores contendo óxido de titânio como principal semicondutor tem sido investigados devido ao fato do $\mathrm{TiO}_{2}$ se apresentar como um dos materiais mais promissores para este fim. Os fotocatalisadores contendo $\mathrm{TiO}_{2}$ vem sendo exaustivamente estudados pelo fato deste óxido ser um material inócuo que apresenta caracteristicas estruturais e fisico-químicas adequadas para atuar como semicondutor. ${ }^{13}$ 
Entretanto, se observam limitações da utilização deste semicondutor com irradiação solar, pois em função do seu grande band gap se torna necessário o uso da radiação ultravioleta para excitar os pares eletron-buracos. ${ }^{14} \mathrm{Com}$ isso, muitos pesquisadores tem tentado otimizar seu desempenho através de associaçao com outros óxidos metálicos e da dopagem com materiais não metálicos. ${ }^{15-17}$ Essas modificações visam melhorar a atividade ótica do fotocatalisador devido ao aumento da condutividade elétrica que permitem a absorção da luz na regiao do visível. ${ }^{13}$

Neste contexto, o intuito deste trabalho foi avaliar a aplicabilidade de materiais nanométricos de $\mathrm{TiO}_{2}, \mathrm{ZnO}$ e $\mathrm{TiO}_{2} / \mathrm{ZnO}$, preparados pelo método Pechini e Adams, ${ }^{18}$ na fotodegradação do herbicida atrazina, que tem sido caracterizado como um composto de elevada toxicidade ao ecossistema.

\section{METODOLOGIA}

\section{Materiais}

Todos os componentes deste experimento foram de grau analítico puro. Metanol 99,8\% (Alphatec), $\mathrm{HCl} 37 \%$ (VETEC), água destilada e deionizada, isopropóxido de titânio IV 97\% (Sigma Aldrich), acetato de zinco 98\% (VETEC), ácido cítrico 99\% (VETEC), etilenoglicol 99,9\% (VETEC), atrazina 99\% (Sigma Aldrich) e acetonitrila 99,9\%.

\section{Preparação das resinas poliméricas}

Os catalisadores de $\mathrm{TiO}_{2}, \mathrm{ZnO}$ e $\mathrm{TiO}_{2} / \mathrm{ZnO}$ foram preparados pelo método Pechini e Adams ${ }^{18}$ através da obtenção de resinas precursoras de titânio e zinco, seguindo os procedimentos descritos a seguir:

- Preparação da resina de titânio: a resina precursora de Titânio, foi preparada pela dissolução de ácido cítrico em etilenoglicol, sob agitação constante, a $65^{\circ} \mathrm{C}$. Após a completa dissolução do ácido, a temperatura foi elevada a $90{ }^{\circ} \mathrm{C}$ para a adição de uma solução de isopropóxido de titânio (em $\mathrm{HCl}$ 1:1) em uma proporção de 1:4:16 em mol de metal, ácido cítrico e etilenoglicol respectivamente. Após ocorrer a completa dissolução do Ti $\left[\mathrm{OCH}\left(\mathrm{CH}_{3}\right)_{2}\right]_{4}$ obteve-se a resina precursora de Titânio.

- Preparação da resina de zinco: a formação da resina precursora de zinco, foi obtida pelo mesmo procedimento descrito para obtenção da resina de titânio, entretanto, neste caso foi utilizado $o$ acetato de zinco como fonte deste metal.

\section{Padronização das resinas}

A padronização das resinas precursoras de titânio e zinco foi realizada pelo método de gravimetria (em triplicata). Para tanto, uma alíquota de $1,0 \mathrm{~g}$ de resina foi transferida para um cadinho de porcelana, previamente limpo e aferido. A resina foi calcinada utilizando-se uma rampa de aquecimento: aquecimento até $100{ }^{\circ} \mathrm{C}$ por 60 minutos; seguido de aquecimento até $400^{\circ} \mathrm{C}$ por 240 minutos e, posteriormente foi mantida a $100{ }^{\circ} \mathrm{C}$ por tempo suficiente para que se obtivesse massa constante de resina. A partir da massa obtida foi calculada a quantidade de metal presente nas soluções precursoras.

\section{Preparação dos catalisadores de dióxido de titânio e óxido de zinco}

Os catalisadores preparados por Pechini foram utilizados na forma de pó ultrafino e para sua preparação foi adicionado ao cadinho uma quantidade conhecida da resina de titânio e da resina de zinco e em seguida adicionou-se uma quantidade conhecida de carbono (Vulcan $\mathrm{XC}$ 72) previamente tratado. Aplicou-se uma rampa de aquecimento de $250^{\circ} \mathrm{C}$, que foi mantida por uma hora e em seguida aplicou-se outra rampa de $400{ }^{\circ} \mathrm{C}$ mantida por mais uma hora formando assim, os catalisadores.

\section{Catalisadores binários}

Os catalisadores binários foram preparados através da mistura de uma quantidade apropriada das resinas precursoras de titânio e zinco obtidas pelo método Pechini para possuir composição nominal $\mathrm{Ti} / \mathrm{Zn}$ (70:30). Adicionou-se à mistura uma quantidade suficiente de carbono (Vulcan XC-72) previamente tratado, a fim de obter uma mistura de catalisador carregado com $30 \%$ de metais. A mistura foi calcinada usando a seguinte rampa de aquecimento: aquecimento até $250{ }^{\circ} \mathrm{C}$, mantido por uma hora, seguido de aquecimento até $400{ }^{\circ} \mathrm{C}$ mantido por mais uma hora, formando assim, o catalisador binário.

\section{Caracterização dos catalisadores}

Os catalisadores foram caracterizados por difração de raios- $\mathrm{X}$ (DRX) e microscopia eletrônica de varredura (MEV).

Para as análises de DRX foi utilizado um difratômetro Bruker D8 Discover com radiação monocromática de tubo anódico de cobre acoplado a um monocromador Johansson para $K \alpha_{1}$ operando em 40 KV e 40 mA, configuração Bragg-Brentano $\theta-2 \theta$, detector unidimensional Lynxeye, intervalo de $2 \theta$ de 20 a $85^{\circ}$, com passo de $0,02^{\circ}$. As amostras foram mantidas em rotação de $15 \mathrm{rpm}$ durante a medida.

Os dados obtidos foram refinados quanto aos parâmetros estruturais, sendo possível assim, identificar a fase presente nas amostras. O tamanho de cristalito foi determinado, para as famílias dos planos cristalográficos $\{\mathrm{hkl}\}$, usando a Equação de Scherrer (Equação 1). ${ }^{19}$

$$
D_{h k l}=\frac{0,9 \lambda}{\beta \cos \theta}
$$

onde: $\mathrm{D}_{\mathrm{hkl}}$ é o tamanho do cristalito, $\lambda$ é o comprimento de onda da radiação utilizada (1,54 $\AA$ ), $\beta$ é a largura a meia altura do pico e $\theta$ o ângulo de difração.

Para as análises de MEV foi utilizado um microscópio eletrônico de varredura marca Jeol, modelo JSM-IT300 do Laboratório de Microscopia do Centro Regional para o Desenvolvimento Tecnológico e Inovação de Goiás (CRTI - GO) e as micrografias foram obtidas com aproximação de 2000 x e 30000x.

\section{Fotocatálise}

\section{Solução de atrazina}

A solução de atrazina foi preparada para obter concentração final de $20 \mathrm{mg} . \mathrm{L}^{-1}$, através da dissolução do padrão analítico do herbicida em metanol e água destilada.

\section{Fotodegradação}

A fotodegradação foi realizada em béquer de vidro, onde foi adicionada a solução de atrazina e $20 \mathrm{mg}$ de nanocatalisador $\left(\mathrm{TiO}_{2}\right.$, $\mathrm{ZnO}, \mathrm{TiO}_{2} / \mathrm{ZnO}$ ). As soluções, contendo os diferentes catalisadores, foram dispostas a uma distância de $12 \mathrm{~cm}$ da fonte de luz em uma câmara de fotoradiação ultravioleta (UV) (Figura 1), equipada com lâmpada de vapor de mercúrio de $125 \mathrm{~W}$. Para efeito de comparação, também foi realizada a fotodegradação de amostras contendo apenas a solução de atrazina sem adição de catalisador (controle). A exposição à radiação ocorreu por tempo máximo de 100 minutos e a cada 10 minutos, alíquotas foram coletadas para análise da absorbância.

A Figura 1 mostra a câmara de fotoreação onde foram realizados os procedimentos de fotodegradação. 

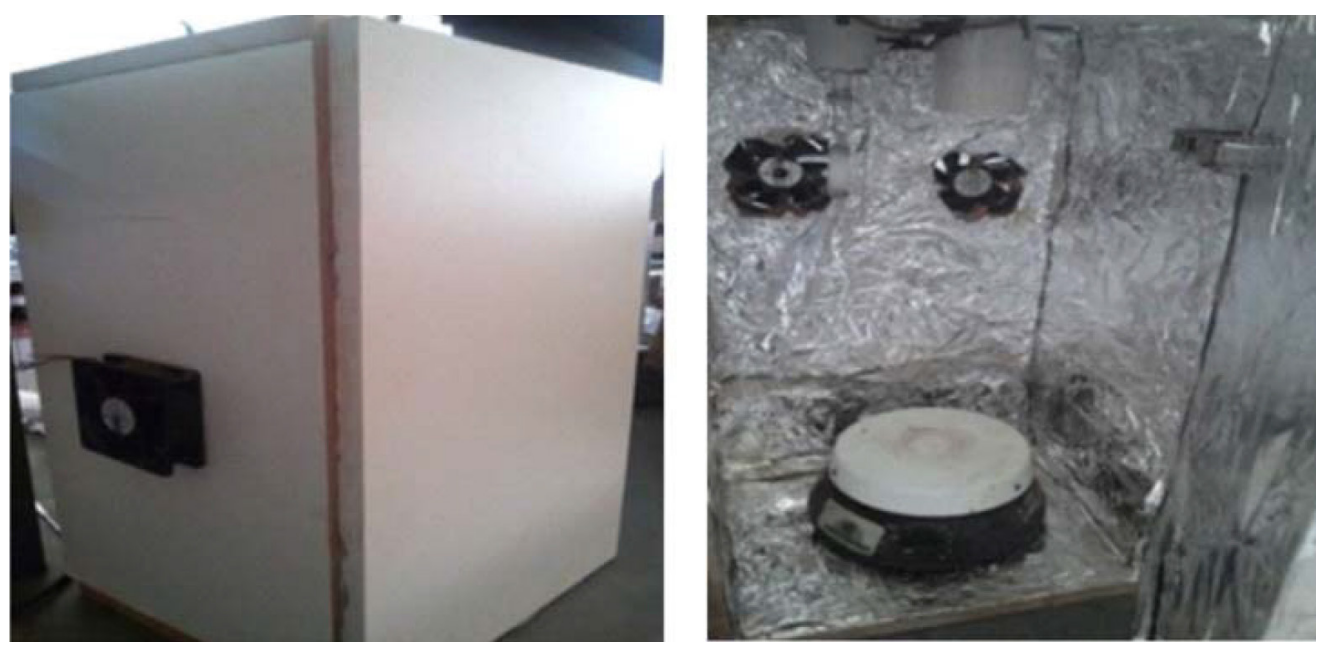

Figura 1. Câmara de fotoreação equipada com uma lâmpada de vapor de mercúrio 125 Watts, um agitador magnético e coolers para resfriamento

\section{Espectroscopia de absorção na região do Ultravioleta e Visível} (UV-vis)

As alíquotas coletadas durante a fotodegradação foram analisadas em espectrômetro Perkin Elmer Lambda 750 in UV-Vis/Nira, com varredura de 200 a $400 \mathrm{~nm}$, disponível na Central Analítica do IFGoiano - Rio Verde, Goiás. Foram usadas cubetas de quartzo, com caminho óptico de $1 \mathrm{~cm}$, para aquisição dos espectros.

\section{Cromatografia Líquida de Alta Eficiência (CLAE)}

As amostras foram analisadas em um cromatógrafo a líquido do Laboratório de Cromatografia e Espectrometria de Massas (LaCEM) do IQ - UFG, modelo 1220 Infinity LC System da empresa Agilent Technologies, equipado com um detector UV-vis e coluna analítica Eclypse C18 (150 mm x 4,6 um, 5 micra) Agilent Technologies, EUA.

A fase móvel consistiu de um gradiente de acetonitrila:água, iniciou-se com 80:20 v/v e um fluxo de 1,4 $\mathrm{mL} \mathrm{min}^{-1}$, após 5 minutos 60:40 v/v fluxo de 2,0 $\mathrm{mL} \mathrm{min}^{-1}$, após 10 minutos 50:50 v/v mantendo o fluxo de $2,0 \mathrm{~mL} \mathrm{~min}^{-1}$ até o término da análise (14 minutos). $\mathrm{O}$ volume de injeção foi de $20 \mu \mathrm{L}$ e a detecção foi realizada em $320 \mathrm{~nm}$.

\section{RESULTADOS E DISCUSSÃO}

\section{Caracterização dos catalisadores}

Difração de raios- $X$

A Figura 2 apresenta o difratograma obtido para a amostra de catalisador de $\mathrm{TiO}_{2}$ preparada pelo método Pechini.

Este processo de caracterização visou avaliar a eficiência da etapa de síntese dos semicondutores (fotocatalisadores) e a estrutura da fase obtida, a qual influência, significativamente, o processo de fotocatálise.

A identificação da fase cristalina obtida por DRX foi realizada por comparação do difratograma das amostras analisadas com o banco de dados JCPDS (Joint Committee on Powder Diffraction Standards).

A análise de DRX do catalisador de dióxido de titânio apresentou apenas a formação da fase cristalina anatase (JCPDS 21-1272), que apresenta os picos de difração identificados na Figura 2. Pelo difratograma se observa alargamento dos picos, o que indica a característica nanométrica das partículas do catalisador. ${ }^{20} \mathrm{O}$ plano utilizado para o cálculo do tamanho de cristalito foi o (101) e o valor calculado, usando-se a equação de Scherrer, para o $\mathrm{TiO}_{2}$ foi de $6,8 \mathrm{~nm}$.

$\mathrm{O}$ difratograma obtido para o $\mathrm{ZnO}$ é apresentado na Figura 3 e foi possível identificar a formação da fase wurtzita (JCPDS 36-1451) através dos picos de difração hkl (100), (002), (101),(102), (110) e

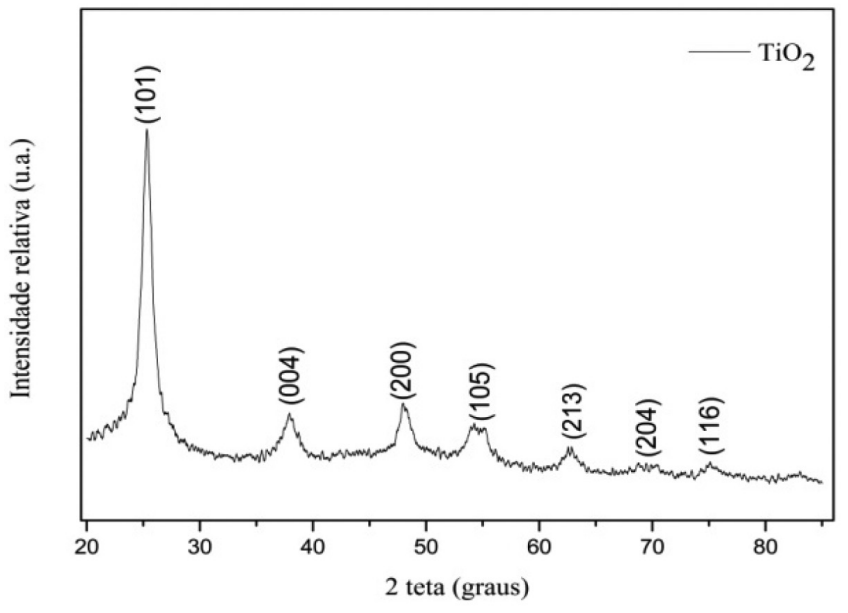

Figura 2. Difratograma do catalisador de $\mathrm{TiO}_{2}$ preparado pelo método Pechini

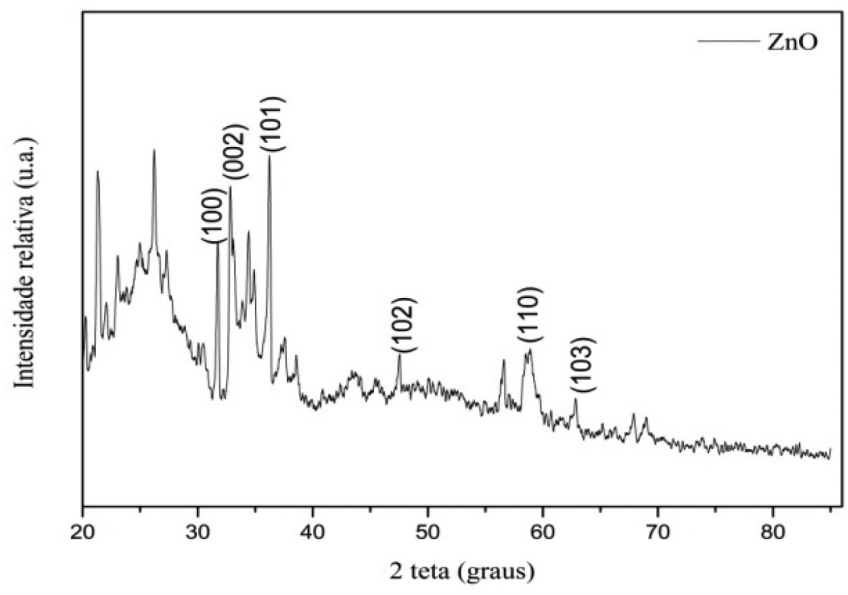

Figura 3. Difratograma do catalisador de ZnOpreparado pelo método Pechini

(103). O tamanho de cristalito calculado, tendo como referência o hkl (101) usando-se a equação de Scherrer foi de $34,5 \mathrm{~nm}$.

A Figura 4 mostra o difratograma obtido para o catalisador binário $\mathrm{TiO}_{2} / \mathrm{ZnO}$. Por este difratograma não foi possível observar os padrões hkl de difração do óxido de zinco, pois houve deslocamento do plano cristalográfico característico do $\mathrm{ZnO}$ para região de 2 teta menor, indicando que o zinco está entrando na fase anatase do $\mathrm{TiO}_{2}$ (JCPDS 21-1272), o que pode indicar a formação de solução sólida 


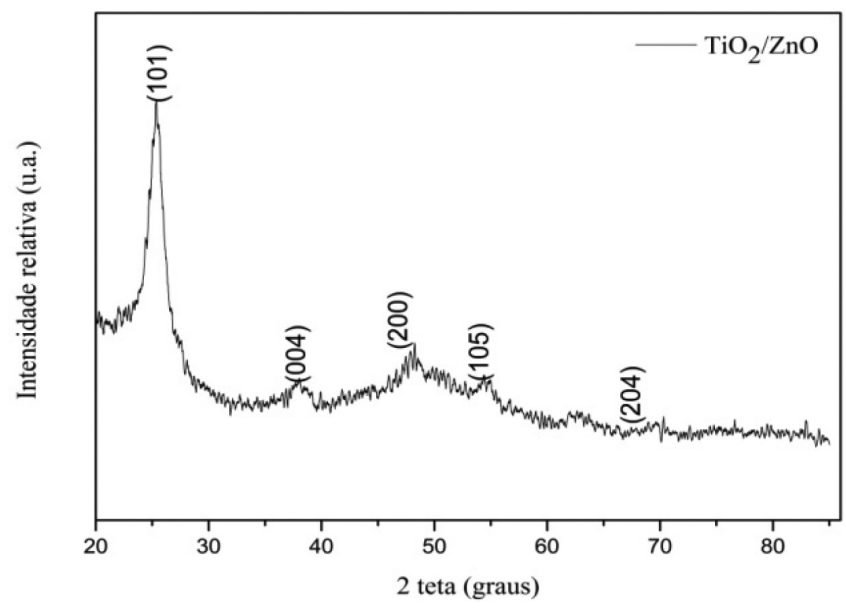

Figura 4. Difratograma do catalisador binário de $\mathrm{TiO}_{2} / \mathrm{ZnO}$ obtido pelo método Pechini

entre os óxidos. Esse catalisador apresentou tamanho de cristalito, usando como base o hkl (101), de 37,3 nm.

Os resultados obtidos por DRX mostram a formação de uma fase anatase estável, tanto para os catalisadores de $\mathrm{TiO} 2$, quanto para os catalisadores binários de $\mathrm{TiO} 2 / \mathrm{ZnO}$. Além disso, todos os catalisadores apresentaram tamanhos de partícula adequados para a utilização em processos de fotocatálise.

Outros métodos de preparo de fotocatalisadores também tem relatado obtenção de materiais que apresentam alta área superficial com tamanhos de partícula da ordem de nanômetros. Bakar e

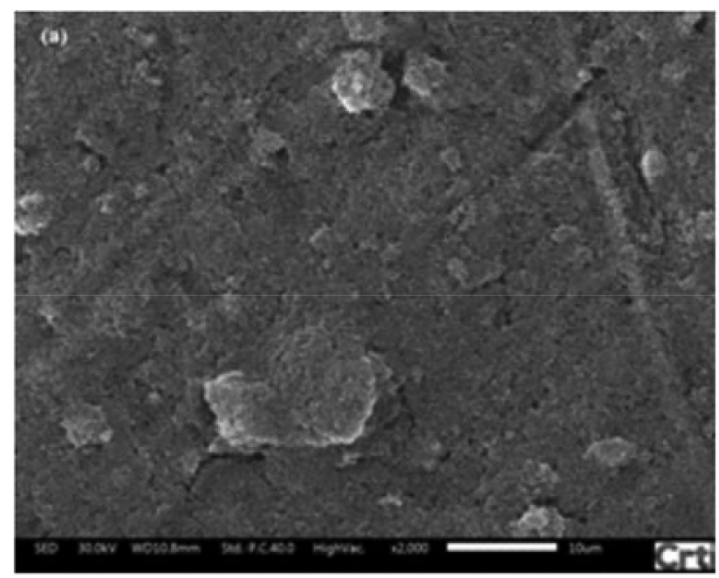

Figura 5. Aspectos morfológicos do pó de TiO2 (a) 2000X e (b) 30000X

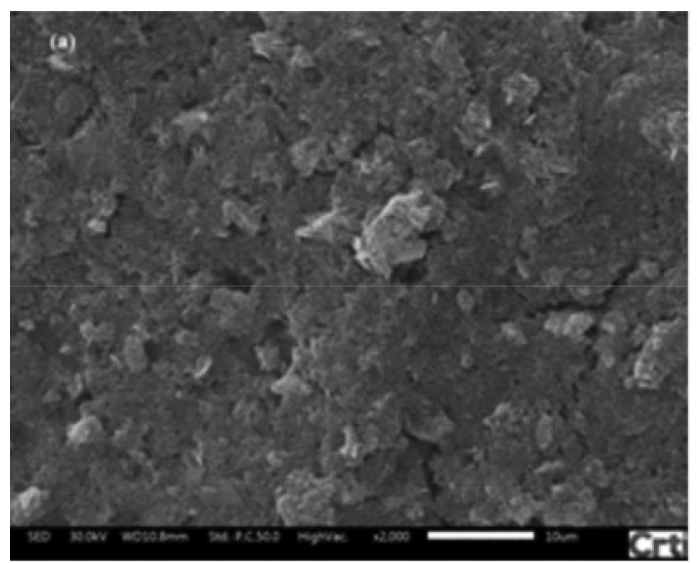

\section{Tigura 5. Aspectos morfologicos do pó de TiO2 (a) $2000 x$ e (b) 30000X}

colaboradores ${ }^{13}$ relataram em seu trabalho de degradação do corante alaranjado de metila com fotocalisadores de $\mathrm{TiO}_{2} \mathrm{~N}$-dopados que os catalisadores com maior quantidade de nitrogênio apresentaram menores tamanhos de partícula.

Neste trabalho, foi observado um aumento no tamanho de partícula para os catalisadores contendo $\mathrm{ZnO}$, entretanto todos os catalisadores possuem partículas na ordem de nanômetros e alta área superficial.

\section{Microscopia Eletrônica de Varredura}

As Figura 5, 6 e 7 mostram as micrografias, obtidas por MEV, das amostras de catalisadores de $\mathrm{TiO} 2, \mathrm{ZnO}$ e $\mathrm{TiO}_{2} / \mathrm{ZnO}$, respectivamente.

Pelas micrografias dos catalisadores (Figuras 5, 6 e 7) verifica-se a formação das nanopartículas e na imagem obtida com o catalisador de $\mathrm{ZnO}$ (Figura 6) fica evidente a formação de aglomerados, que podem estar relacionados a sinterização do material, devido ao processo de preparação dos catalisadores envolver a calcinação dos mesmos em temperaturas relativamente elevadas.

A morfologia dos catalisadores de óxido de zinco apresentaram aglomerados grandes, com característica de blocos densos com tamanho irregulares e heterogêneos de aspecto rígido. Além disso, se observa uma variação dos tamanhos de aglomerado que se apresentam na faixa de $0,5 \mu \mathrm{m}$.

\section{Fotocatálise}

Espectroscopia de absorção na região do UV-vis

$\mathrm{O}$ intuito de usar esta técnica foi para compreender melhor a interação da matéria com a radiação UV e acompanhar os ensaios

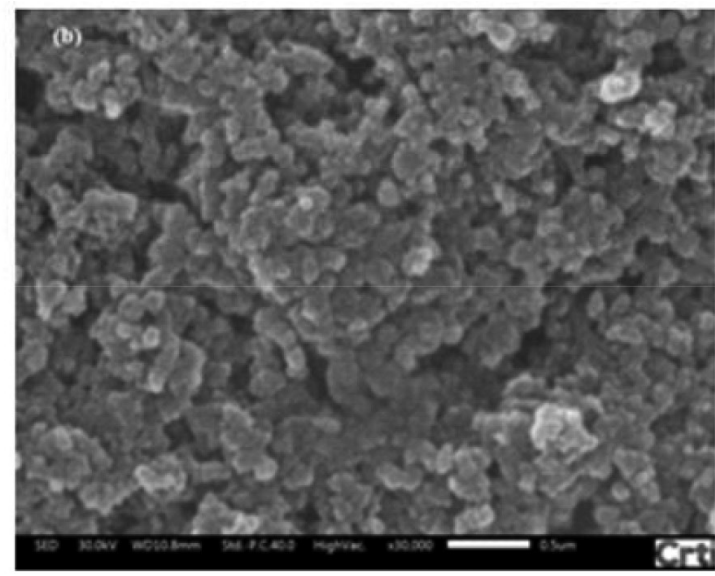

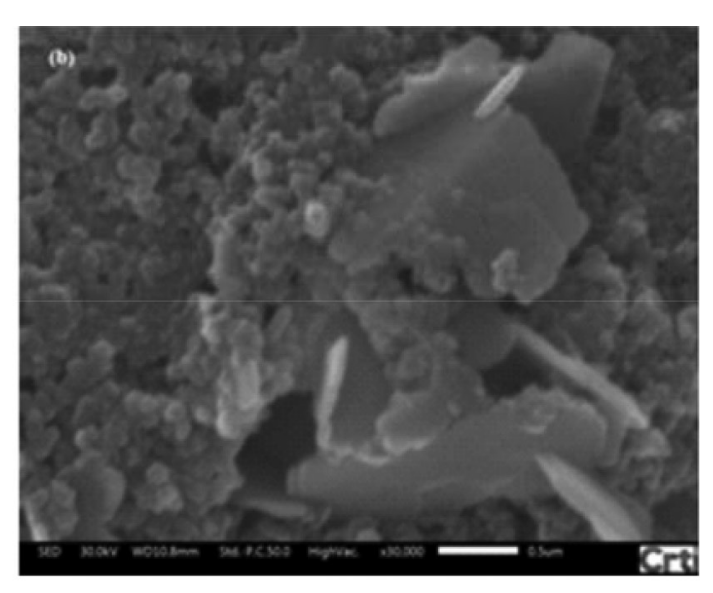

Figura 6. Aspectos morfológicos do pó de ZnO (a) 2000X e (b) $30000 \mathrm{X}$ 


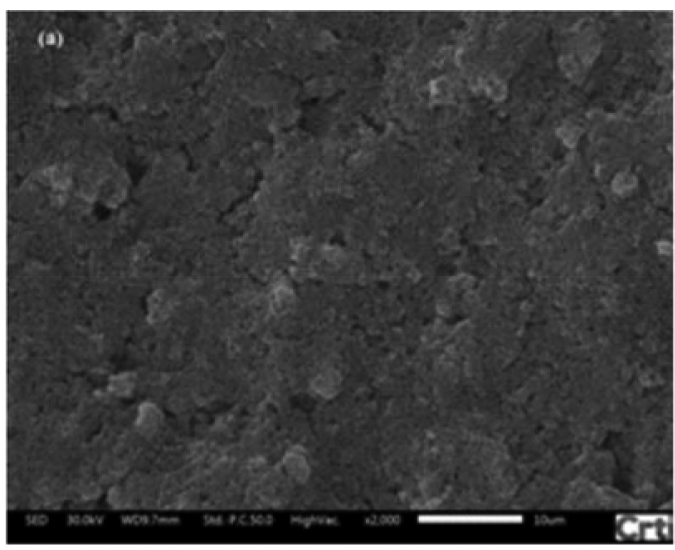

Figura 7. Aspectos morfológicos do pó de $\mathrm{TiO}_{2} / \mathrm{ZnO}$ (a) 2000X e (b) $30000 \mathrm{X}$

de fotodegradação, catalisado pelas nanopartículas.

Como a atrazina pode sofrer fotólise, foi realizada a fotodegradação deste herbicida, sem a adição de catalisadores, apenas por irradiação direta de luz UV e os resultados obtidos são apresentados na Figura 1S.

Pelos valores de absorbância obtidos no tempo zero, início da fotólise, são observados 2 picos característicos da atrazina, que correspondem as transições eletrônicas que ocorrem de $\varpi$ para $\varpi^{*}(222$ $\mathrm{nm})$ e $n$ para $\varpi^{*}(265 \mathrm{~nm}) .^{21}$

Após 10 minutos de irradiação se observa o decaimento da absorbância dos picos características da atrazina em 222 e 265 nm, o que evidencia a ocorrência da degradação do herbicida.

Além disso, a partir de 30 minutos de reação é possível observar o aumento da absorbância nos comprimentos de onda de 210 e $237 \mathrm{~nm}$, que estão relacionados à formação de subprodutos de degradação da atrazina, sendo o pico em $210 \mathrm{~nm}$ relacionado ao composto desetilatrazina e o pico em $237 \mathrm{~nm}$ associado à formação da hidroxiatrazina, que é um dos principais subprodutos formados na degradação deste herbicida. ${ }^{22}$ Estes compostos são normalmente encontrados em comprimentos de onda de 212 e $240 \mathrm{~nm}$, entretanto, pequenos desvios, relacionados à formação dos subprodutos em processos de degradação, podem ser encontrados em análises qualitativas..$^{22,23}$

Os processos de fotodegradação na presença dos catalisadores de $\mathrm{TiO}_{2}, \mathrm{ZnO}$ e $\mathrm{TiO}_{2} / \mathrm{ZnO}$ também foram acompanhados por espectroscopia de absorção na região do UV-vis e os resultados obtidos são apresentados na Figura 2S.

Para todos os processos fotocatalíticos foi possível observar o mesmo comportamento de formação de subprodutos obtido para a fotólise direta, com a diminuição dos picos de absorbância característicos da atrazina e o aumento da absorbância (na região de 210 e $237 \mathrm{~nm}$ ) dos picos relacionados aos subprodutos formados. Após 100 minutos de irradiação, a menor absorbância da atrazina foi detectada com a utilização das nanopartículas de óxido de zinco, o que se evidencia através do cálculo das concentrações de atrazina que será discutido posteriormente.

O monitoramento da degradação da atrazina foi realizado através dos dados de absorbância obtidos no comprimento de onda de 222 nm. Porém, dependendo da via mecanística da fotodegradação desse herbicida, pode ocorrer à formação de subprodutos com absorbância na mesma região, o que ocasiona a sobreposição de picos. ${ }^{23}$

Os principais compostos formados na degradação da atrazina, segundo Gevão e colaboradores são compostos hidroxilados e clorados, com os compostos clorados apresentando toxicidade semelhante à atrazina, ${ }^{24} \mathrm{e}$ dentre eles podem ser citados:

- Desetilatrazina (2-cloro-4-amino-6-isopropilamino-s-triazinaDEA);

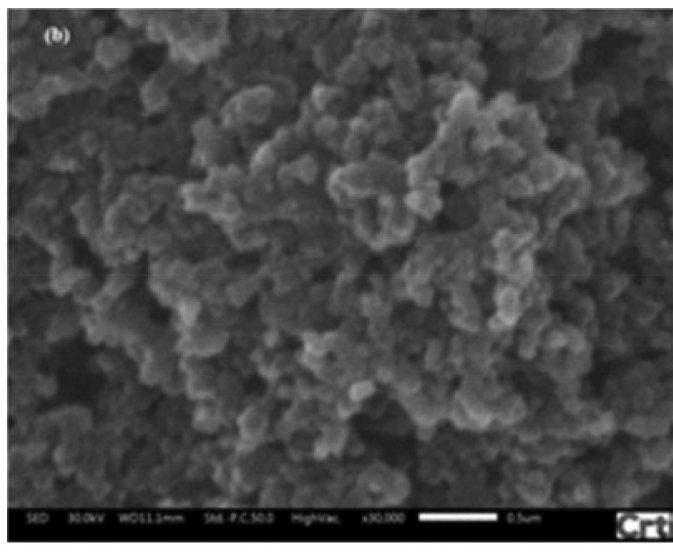

- Deisopropilatrazina (2-cloro-4-etilamino-6-amino-s-triazina DIA);

- Desetildeisopropilatrazina (2-cloro-4,6-amino-s-triazina - DEDIA);

- Desetilhidroxiatrazina (2-hidroxi-4-amino-6-isopropilamino-s-triazina - DEHA);

- Deisopropilhidroxiatrazina (2-hidroxi-4-etilamino-6-amino-s-triazina - DIHA) e

- Hidroaxiatrazina (2-hidroxi-4-etilamino-6-isopropilamino-s-triazina - HA).

Os principais subprodutos de degradação da atrazina estão representados na Figura $3 S^{25}$

Uma curva de calibração da concentração de atrazina foi construída pelos valores de absorbância na região do UV-Vis. Através dos dados obtidos traçou-se uma curva de regressão linear, apresentada na Figura 4S, onde se obteve valor de $\mathrm{R}^{2}=0,9976$, e equação da reta $\mathrm{y}=$ $8,3845 \mathrm{x}-0,50911$. As concentrações obtidas através degradação da atrazina frente a sua estrutura inicial foram determinadas em partes por milhão (ppm) de atrazina para todo o período de fotodegradação.

Os valores de absorbância obtidos na fotodegradação (Figura $2 \mathrm{~S})$ foram utilizados para estimar as concentrações da atrazina no decorrer da degradação, onde foram utilizadas a equação da reta e a absorbância no comprimento de onda de $222 \mathrm{~nm}$. Assim, a concentração da atrazina foi calculada e os resultados obtidos são apresentados na Tabela 1.

Tabela 1. Valores calculados para a concentração da atrazina (ppm), no decorrer da degradação, na presença de catalisadores nanoestruturados

\begin{tabular}{ccccc}
\hline Tempo & Fotólise & $\mathbf{T i O}_{2}$ & $\mathbf{Z n O}$ & $\mathbf{T i O}_{2} / \mathbf{Z n O}$ \\
\hline 0 & 18,24 & 18,24 & 18,24 & 18,24 \\
10 & 14,05 & 12,88 & 10,43 & 12,23 \\
20 & 12,45 & 9,33 & 9,48 & 9,71 \\
30 & 10,50 & 10,07 & 7,79 & 8,17 \\
40 & 10,32 & 8,33 & 7,37 & 7,87 \\
50 & 9,04 & 7,77 & 6,95 & 7,34 \\
60 & 10,55 & 10,99 & 6,87 & 6,90 \\
70 & 9,43 & 6,86 & 6,20 & 7,59 \\
80 & 9,25 & 8,66 & 7,11 & 7,15 \\
90 & 9,27 & 6,88 & 6,92 & 7,43 \\
100 & 9,98 & 8,23 & 7,13 & 8,04 \\
\hline
\end{tabular}

A fotocatálise, utilizando diferentes catalisadores, foi realizada para comparar a influência do tipo de catalisador, na degradação da molécula do herbicida.

Conforme dito anteriormente e demonstrado pelos resultados apresentados na Tabela 1, é possível observar, que após 100 minutos de reação, a menor concentração da atrazina $(7,13 \mathrm{ppm})$ foi 
detectada com a utilização das nanopartículas de óxido de zinco. Entretanto, se observa uma pequena variação nas concentrações de atrazina, considerando-se o tempo de degradação, o que pode ser explicado pela sobreposição dos picos de absorbância da atrazina e dos subprodutos formados.

\section{Cromatografia Líquida de Alta Eficiência (CLAE)}

Ainda com o intuito de avaliar a degradação do herbicida atrazina foi utilizada a técnica de cromatografia líquida de alta eficiência na separação das substâncias observadas na fotodegradação. A Figura 5S apresenta os cromatogramas obtidos para o padrão de atrazina e material fotodegradado, após 100 minutos, na presença dos catalisadores de $\mathrm{TiO}_{2}, \mathrm{ZnO}$ e $\mathrm{TiO}_{2} / \mathrm{ZnO}$, respectivamente.

Pelos cromatogramas da Figura 5S (a) é possível observar que o pico principal do herbicida aparece no tempo de retenção de 8 minutos e não aparece na amostra referente à análise após $100 \mathrm{mi}$ nutos de irradiação, isso evidencia que as nanopartículas de titânio promoveram a degradação da atrazina.

No tratamento com nanopartículas de $\mathrm{ZnO}$ e $\mathrm{TiO}_{2} / \mathrm{ZnO}$ (Figura $5 \mathrm{~S}$ (b) e (c)) também se observa-se o pico da atrazina em 8 minutos, entretanto, após 100 minutos de reação, o pico não desaparece, mas apresenta intensidade bem menor à observada inicialmente, constatando também a degradação do herbicida.

Além disso, a observação de picos em tempos de retenção distintos indica a formação de subprodutos de degradação, o que também já foi constatado pelas análises de espectroscopia na região do UV-Vis.

\section{CONCLUSÃO}

Os materiais sintetizados apresentaram escala nanométrica, o que pode ser confirmado através das análises de microscopia eletrônica de varredura e difração de raios-X e o catalisador que apresentou menor tamanho de partícula foi o de dióxido de titânio.

A utilização do catalisador de $\mathrm{ZnO}$, apesar de apresentar partículas um pouco maiores, mas ainda sendo considerado como nanoestruturado, quando utilizado no processo de fotocatálise heterogênea, mostrou-se eficaz pela formação de radicais $\mathrm{O}_{2} \bullet$ e $\mathrm{OH} \bullet \mathrm{em}$ meio aquoso, na degradação da molécula da atrazina. A partir das análises de UV-Vis, utilizando este catalisador, se observou o maior decaimento de absorbância ao longo da fotodegradação e as análises cromatográficas apresentaram a redução significativa deste herbicida e a formação de outros compostos como subprodutos da degradação desse agroquímico.

Entretanto, estudos posteriores devem ser realizados a fim de identificar os subprodutos formados e visando verificar os efeitos de toxicidade relacionados à eles.

\section{AGRADECIMENTOS}

A Coordenação de Aperfeiçoamento do Pessoal de Nível Superior, ao Instituto Federal Goiano Campus Rio Verde e a Universidade Federal de Goiás Câmpus Samambaia.

\section{REFERÊNCIAS}

1. Carneir, F. F; Pignati, W; Rigotto, R.M.; Dossiê ABRASCO, $1^{\text {th }}$ ed., Expressão Popular: Rio de janeiro, 2012.

2. Jardim, I. C.; Andrade, J. A.; Queiroz, S. C; Quim. Nova 2009, 32, 996.

3. Rangel, C. F.; Rosa, A. C. S.; Sarcinelli, P. N.; Caderno Saúde Coletiva 2011, 19, 435.

4. Egler, M; Dissertação de Mestrado, Escola Nacional de Saúde Pública da Fiocruz, Brasil, 2002.

5. http://www3.epa.gov/pesticides/chem_search/reg_actions/reregistration/ red_PC-080803_1-Apr-06.pdf, acessada em dezembro 2015.

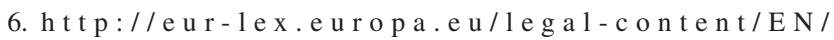
TXT/?uri=celex\%3A31991L0414, acessada em janeiro 2016.

7. http://www.mma.gov.br/port/conama/res/res05/res35705.pdf, acessada em novembro 2014.

8. ht t p : / / e ur-1ex.europa.eu/legal-content/EN/ TXT/?uri=CELEX\%3A32004D0248, acessada em janeiro 2016.

9. Arques, A.; Amat, A. M.; Garcia-Ripool, A.; Vicente, R; J. Hazard. Mater. 2007,146, 447 .

10. Bagal, M. V.; Gogate, P. R.; Ultrason. Sonochem. 2014, 21, 1.

11. Brito, N. N.; Silva, V. B. M.; Revista Eletrônica de Engenharia Civil 2012, 1, 36 .

12. Mills, A.; Davies, R. H.; Worsley, D.; Chem. Soc. Rev. 1993, $22,417$.

13. Bakar, S. A.; Byzynski, G.; Ribeiro, C.; J. Alloys Compd. 2016, 666, 38.

14. Bakar, S. A.; Ribeiro, C.; J. Mol. Catal. A: Chem. 2016, 421, 1.

15. Dozzi, M. V.; Marzorati, S.; Longhi, M.; Coduri, M.; Artiglia, L.; Selli, E.; Appl. Catal., B 2016, 186, 157.

16. Bakar, S. A.; Ribeiro, C.; J. Mol. Catal. A: Chem. 2016, 412, 78.

17. Bakar, S. A.; Ribeiro, C.; J. Photochem. Photobiol., C 2016, $27,1$.

18. Pechini, M. P.; Adams; N. United States Patent, 3330697, 1967.

19. Klung, H.; Alexander, L.; X-ray diffraction procedures, Wiley: New York, EUA, 1962.

20. Neiva, L. S.; Costa, A. C. F. M.; Andrade, H. M. C.; Gama, L.; Cerâmica 2012, 58, 186.

21. Chena, C.; Yanga, S.; Guob, Y.; Suna, C.; Xuc, B.; J. Hazardous Materials 2009, 172, 675.

22. Moreira, A. J.; Dissertação de Mestrado, Universidade Federal de Alfenas, Brasil, 2014

23. Mourão, H. A. J. L.; Malagutti, A. R.; Ribeiro, C.; Appl. Catal. A- Gen. 2010, 382, 284.

24. Gevão, B.; Semple, K. T.; Jones, K. C.; Environ. Pollut. 2000, 108, 3.

25. Scribner, E. A.; Thurman, E. M.; Zimmerman, L. R.; Science Tot. Environment 2000, 248, 157. 